\title{
Rule 1: Know Your Stuff
}

\author{
Bettelou Los \\ University of Edinburgh \\ B.Los@ed.ac.uk
}

\begin{abstract}
Syntax is not the right arena to make a case for language family relationships.
\end{abstract}

\section{Keywords}

historical syntax - language contact - history of English - Germanic

There are many languages of which the question which family it belongs to is not easy to answer. The South American language Media Lengua has roots almost exclusively from Spanish, but affixes and enclitics from Quechua (Muysken, 2015: 121). Emonds and Faarlund (E\&F) in their book English: The Language of the Vikings seem to think that a list of similarities between Middle English (ME) and Old Norse (ON), and of differences between English and the other West-Germanic languages, is enough to establish that Middle English is North Germanic. Do they make a convincing case?

The first point to note is that many items on the list are factually untrue. It is not true that oE did not, and Dutch and German do not, have preposition stranding or phrasal verbs (Los et al., 2012). What has happened in ME is that the change in the headedness of the VP, which will affect not only the position of the object but also any other dependents (adverbials, predicates), has made the separable particles of the phrasal verbs, as grammaticalized predicates, and the stranded prepositions, as adverbials, appear in post- rather than preverbal position (see also, e. g., Kroch and Taylor, 2000: 147). To name another point, subject-to-subject-raising is also available in Dutch. For subjectto-object raising, the English innovation with verbs of thinking and declaring has the to-infinitive, not the bare infinitive as in oN; and it takes until Late Middle/Early Modern English before we get robust attestations that are not 
inspired by a Latin Vorlage (see Warner, 1982; Dreschler, 2015). They are usually in the passive in English, and emerge for independent reasons, to address the decline of adverbials as unmarked themes after the loss of v2 (Los, 2009).

Another reason why E\&F fail to make their case is the quality of the argumentation. You cannot claim that a change (in casu the vo change) is unlikely to be an independent change in the case of one language $(\mathrm{ME})$ but not in the case of another (ON). The change is not "rare" (p. 66), witness the large numbers of both ov and vo languages occurring within the same language families (Dunn et al., 2011). The claim that "a small number of post-head object DPs in Old English [...] would not easily suffice to cause a massive and central word order change" (p. 66) is misleading in view of the vast number of postverbal objects in OE whose underlying structure (derived from base vo? Or extraposed from base ov?) is analytically ambiguous or indeterminate, and may easily have led a new generation to reanalyze to base vo, particularly in a situation of language contact.

The quality of the argumentation is further undermined by the cavalier treatment of serious counterarguments. The core of West Germanic vocabulary in English is dismissed by claiming that re-borrowing into ME may have happened in a handful of cultural domains unknown to on speakers, e. g. Christianity; the claim that these semantic domains would account for "many hundreds (quite possibly thousands)" of re-borrowings (p. 41) is wholly unsupported.

The same goes for the presence of ov orders in ME. Negated objects remain robustly present in ME, but this is, of course, because on also has them. However, there are plenty of non-negated postverbal objects around until as late as 1400 (Fischer et al., 2000: 175, 177) - it is only after that date that the only preverbal objects are negated objects. The claim that " $[\mathrm{t}]$ he rare head-final vPs in the later periods can be attributed to the influences of surviving Old English dialects in bilingual writers" (p. 64) is, without any further support (which writers? which texts?), not enough to refute this serious counterargument.

What is at the heart of E\&F's problems is that syntax is not the right arena to fight a case for family relationships. Word orders are grounded in general processes of human cognition/conceptualization to a much greater extent than other levels of linguistic description, which means that there is a lot of convergence going on with languages arriving completely independently at the same structures.

As an example, consider the similar pronominal/nominal asymmetry with respect to objects of phrasal verbs in PDE and in North Germanic (examples (22)-(23) on pp. 71-72). It follows a general cognitive pattern of "given" before "new" information, with both full NP objects and particles competing for the end-focus position, while pronouns_- "given" by definition—are unlikely to 
enter that competition (unless heavily focused). In other words, there is nothing special about these outcomes in the two languages, as they both play out in the force field set up by vo/non-v2 syntax and information structure (see, e. g., Los et al., 2012).

\section{References}

Dreschler, Gea. 2015. Passives and the Loss of Verb Second: A Study of Syntactic and Information-Structural Factors. Lот Dissertations in Linguistics 402. Utrecht: LOT.

Dunn, Michael, Simon J. Greenhill, Stephen C. Levinson, and Russell D. Gray. 2011. Evolved structure of language shows lineage-specific trends in word-order universals. Nature 473: 79-82.

Fischer, Olga, Ans van Kemenade, Willem Koopman, and Wim van der Wurff. 2000. The Syntax of Early English. Cambridge: Cambridge University Press.

Kroch, Anthony S. and Ann Taylor. 200o. Verb-object order in early Middle English. In Susan Pintzuk, George Tsoulas, and Anthony Warner (eds.), Diachronic Syntax: Models and Mechanisms, 132-163. Oxford: Oxford University Press.

Los, Bettelou. 2009. The consequences of the loss of verb-second in English: Information structure and syntax in interaction. English Language and Linguistics 13(1): 97-125.

Los, Bettelou, Corrien Blom, Geert Booij, Marion Elenbaas, and Ans van Kemenade. 2012. Morphosyntactic Change: A Comparative Study of Particles and Prefixes. Cambridge: Cambridge University Press.

Muysken, Pieter. 2015. Relexification, and other language contact scenarios for explaining substrate effects. In Pieter Muysken, Norval Smith, and Robert Borges (eds.), Surviving the Middle Passage: the West Africa-Surinam Sprachbund, 107-133. Berlin: De Gruyter.

Warner, Anthony R. 1982. Complementation in Middle English and the Methodology of Historical Syntax. London: Croom Helm. 